\title{
Broadband cavity-enhanced absorption spectroscopy in the ultraviolet spectral region for measurements of nitrogen dioxide and formaldehyde
}

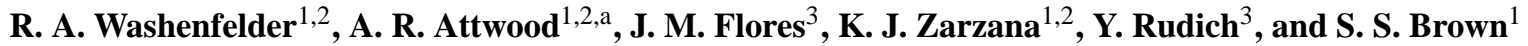 \\ ${ }^{1}$ Cooperative Institute for Research in Environmental Sciences, University of Colorado, 216 UCB, Boulder, CO 80309, USA \\ ${ }^{2}$ Chemical Sciences Division, Earth System Research Laboratory, National Oceanic and Atmospheric Administration, \\ 325 Broadway, Boulder, CO 80305, USA \\ ${ }^{3}$ Weizmann Institute of Science, Department for Earth and Planetary Sciences, Rehovot 76100, Israel \\ anow at: Horiba Scientific, Edison, New Jersey, USA
}

Correspondence to: R. A. Washenfelder (rebecca.washenfelder@noaa.gov)

Received: 20 August 2015 - Published in Atmos. Meas. Tech. Discuss.: 24 September 2015

Revised: 25 November 2015 - Accepted: 8 December 2015 - Published: 15 January 2016

\begin{abstract}
Formaldehyde $\left(\mathrm{CH}_{2} \mathrm{O}\right)$ is the most abundant aldehyde in the atmosphere, and it strongly affects photochemistry through its photolysis. We describe simultaneous measurements of $\mathrm{CH}_{2} \mathrm{O}$ and nitrogen dioxide $\left(\mathrm{NO}_{2}\right)$ using broadband cavity-enhanced absorption spectroscopy in the ultraviolet spectral region. The light source consists of a continuous-wave diode laser focused into a Xenon bulb to produce a plasma that emits high-intensity, broadband light. The plasma discharge is optically filtered and coupled into a $1 \mathrm{~m}$ optical cavity. The reflectivity of the cavity mirrors is $0.99930 \pm 0.00003(1-$ reflectivity $=700 \mathrm{ppm}$ loss $)$ at $338 \mathrm{~nm}$, as determined from the known Rayleigh scattering of $\mathrm{He}$ and zero air. This mirror reflectivity corresponds to an effective path length of $1.43 \mathrm{~km}$ within the $1 \mathrm{~m}$ cell. We measure the cavity output over the 315-350 nm spectral region using a grating monochromator and charge-coupled device array detector. We use published reference spectra with spectral fitting software to simultaneously retrieve $\mathrm{CH}_{2} \mathrm{O}$ and $\mathrm{NO}_{2}$ concentrations. Independent measurements of $\mathrm{NO}_{2}$ standard additions by broadband cavity-enhanced absorption spectroscopy and cavity ring-down spectroscopy agree within $2 \%$ (slope for linear fit $=1.02 \pm 0.03$ with $r^{2}=$ 0.998). Standard additions of $\mathrm{CH}_{2} \mathrm{O}$ measured by broadband cavity-enhanced absorption spectroscopy and calculated based on flow dilution are also well correlated, with $r^{2}=0.9998$. During constant mixed additions of $\mathrm{NO}_{2}$ and $\mathrm{CH}_{2} \mathrm{O}$, the $30 \mathrm{~s}$ measurement precisions $(1 \sigma)$ of the cur-
\end{abstract}

rent configuration were 140 and $210 \mathrm{pptv}$, respectively. The current $1 \mathrm{~min}$ detection limit for extinction measurements at $315-350 \mathrm{~nm}$ provides sufficient sensitivity for measurement of trace gases in laboratory experiments and groundbased field experiments. Additionally, the instrument provides highly accurate, spectroscopically based trace gas detection that may complement higher precision techniques based on non-absolute detection methods. In addition to trace gases, this approach will be appropriate for measurements of aerosol extinction in ambient air, and this spectral region is important for characterizing the strong ultraviolet absorption by brown carbon aerosol.

\section{Introduction}

Formaldehyde $\left(\mathrm{CH}_{2} \mathrm{O}\right)$ is the most abundant carbonyl compound in the atmosphere, with typical tropospheric concentrations between 0.1 and 10 parts per billion (ppbv; Grosjean et al., 1996; Fried et al., 2002). Its sources include secondary photochemical production from biogenic and anthropogenic volatile organic compounds (VOCs) and primary emissions from combustion sources. A Bayesian inverse model of satellite columns shows that the largest global $\mathrm{CH}_{2} \mathrm{O}$ source is oxidation of isoprene and other biogenic VOCs, followed by biomass burning and oxidation of anthropogenic VOCs (Shim et al., 2005). Formaldehyde is lost through photolysis 
and reaction with $\mathrm{OH}$, with an atmospheric lifetime of a few hours. These processes contribute to net ozone production and radical recycling.

The existing in situ measurement techniques for formaldehyde can be broadly categorized as wet chemistry, mass spectrometry, and optical spectroscopy. The wet chemical methods include chromatographic detection of formaldehyde products with 2,4-dinitrophenylhydrazine (Fung and Grosjean, 1981; Lee et al., 1998; Spaulding et al., 2002) and fluorimetric detection of formaldehyde products from Hantzsch (Kelly and Fortune, 1994; Junkermann and Burger, 2006) or other reactions (Kok et al., 1990; Fan and Dasgupta, 1994). These wet chemical methods are sensitive, but they lack rapid time response and are susceptible to chemical interferences (Hak et al., 2005). Formaldehyde has been measured by mass spectrometry using proton transfer reaction mass spectrometry (PTR-MS; Karl et al., 2003; Steinbacher et al., 2004; Wisthaler et al., 2008; Warneke et al., 2011). These measurements are rapid and sensitive but are complicated by strong humidity dependence (Warneke et al., 2011). Spectroscopic measurements of formaldehyde exploit its strong absorption features in the infrared or ultraviolet spectral regions, with detection by Fourier transform infrared spectroscopy (Yokelson et al., 1996), tunable diode laser absorption spectroscopy (Fried et al., 1997, 2002), difference frequency generation absorption spectroscopy (Weibring et al., 2007), and quantum cascade laser spectroscopy (Herndon et al., 2007). Formaldehyde has also been measured spectroscopically by observing its fluorescence near $354 \mathrm{~nm}$ (Mohlmann, 1985; Hottle et al., 2009). Remote sensing instruments for groundbased (Platt et al., 1979; Heckel et al., 2005) and satellitebased (Bovensmann et al., 1999; Burrows et al., 1999) observations use differential optical absorption spectroscopy (DOAS).

Broadband cavity-enhanced absorption spectroscopy (BBCEAS) is a sensitive technique for direct absorption measurements. Compared to wet chemistry, mass spectrometry, and fluorescence, a key advantage of this approach is the inherent accuracy of direct absorption measurements. BBCEAS uses a broadband light source, typically a light emitting diode (LED) or arc lamp, coupled to a high-finesse optical cavity (Fiedler et al., 2003). The light output from the cavity is dispersed with a monochromator and measured using a multichannel detector. Conceptually, it is similar to a conventional optical absorption instrument with a multipass cell, but the high-finesse cavity allows an effective path length of several kilometers in the ultraviolet spectral region and tens or hundreds of kilometers in the visible spectral region. Standard spectral fitting methods can be used to retrieve multiple absorbers because absorption information is acquired simultaneously for a wide wavelength region (Ball et al., 2004; Washenfelder et al., 2008). BBCEAS and the related cavity-enhanced DOAS (CE-DOAS) technique have been successfully used to measure trace gas and aerosol extinction in the visible spectral range (Ball et al., 2004; Langridge et al., 2006; Venables et al., 2006; Washenfelder et al., 2008; Thalman and Volkamer, 2010) and near-ultraviolet spectral range (Gherman et al., 2008; Langridge et al., 2009; Axson et al., 2011; Kahan et al., 2012; Washenfelder et al., 2013). However, only a few measurements have been demonstrated in the ultraviolet spectral region below $340 \mathrm{~nm}$. These include measurements of $\mathrm{O}_{3}, \mathrm{O}_{4}$, and $\mathrm{SO}_{2}$ at $335-375 \mathrm{~nm}$ (Chen and Venables, 2011), measurements of nitrophenols at $320-450 \mathrm{~nm}$ (Chen et al., 2011), and measurements of acetone near $280 \mathrm{~nm}$ (Islam et al., 2013).

Despite the distinct advantages of BBCEAS that have made it a powerful technique for trace gas measurements in the visible spectral region, there are multiple challenges in the ultraviolet that have precluded the measurement of atmospheric trace gases or aerosol extinction at ambient levels. First, LED sources are widely used at visible wavelengths because they are spectrally powerful, inexpensive, lightweight, and consume little power. However, LEDs with high optical power are unavailable at wavelengths shorter than $365 \mathrm{~nm}$. Second, the optical bandpass filters required to reject out-ofband light from broadband sources are less efficient in the ultraviolet spectral region. Third, Rayleigh scattering by ambient air increases inversely with the fourth power of wavelength, $\lambda^{-4}$, and can become a significant loss process that limits light intensity and optical path length for an optical cavity in the ultraviolet spectral region. Finally, the thin film coatings used in the fabrication of high reflectivity cavity mirrors are less efficient in the ultraviolet spectral region, with greater absorption and scattering losses in the material. To the extent that these challenges can be overcome, BBCEAS measurements in the ultraviolet spectral region may be a powerful technique for atmospheric spectroscopy due to the large number of trace gases with structured absorption in this region and to the importance of aerosol absorption.

In this work, we report the first laboratory measurements of formaldehyde by BBCEAS in the ultraviolet spectral region at $315-350 \mathrm{~nm}$. The approach uses a novel laser-driven Xe plasma as the high-power ultraviolet light source. This source eliminates some of the issues associated with conventional arc lamps, including large size, heat dissipation, and instability in the arc location. Although challenges remain for atmospheric sampling, this approach brings the $\mathrm{CH}_{2} \mathrm{O}$ detection limit into the range of ambient concentrations. The subsequent sections describe instrumentation, data analysis, and results. The design requirements for ultraviolet BBCEAS to achieve trace gas detection at background $\mathrm{CH}_{2} \mathrm{O}$ mixing ratios with $1 \mathrm{~min}$ time resolution are discussed in the conclusions. 

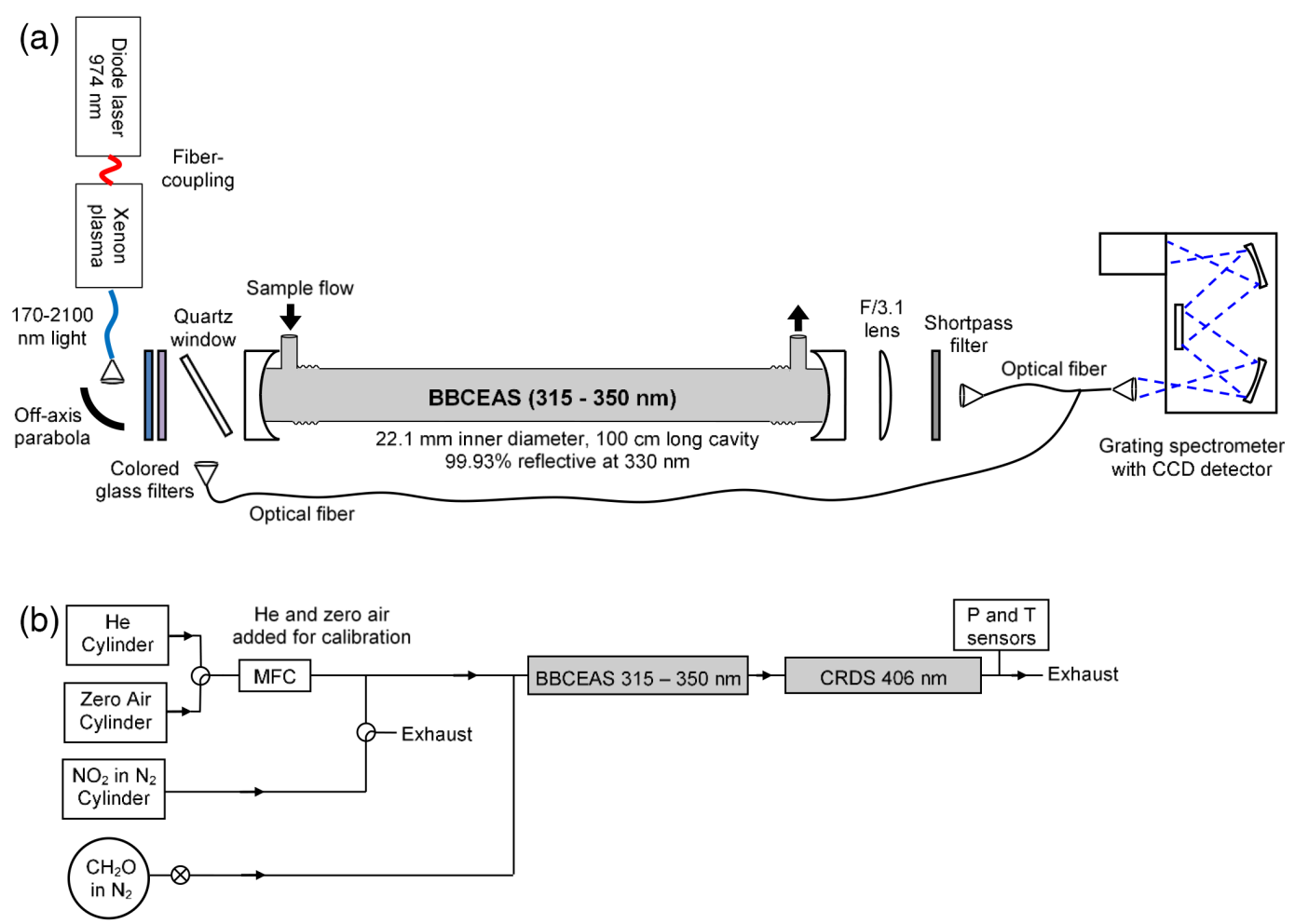

Figure 1. (a) Schematic of the broadband cavity-enhanced absorption spectrometer, showing the laser-driven arc lamp, collimating optics, cavity, and spectrometer. (b) Block diagram showing the flow system to introduce He, zero air, $\mathrm{CH}_{2} \mathrm{O}$, and $\mathrm{NO}_{2}$ to the two instruments.

\section{Experimental}

\subsection{Description of the BBCEAS instrument}

As shown in Fig. 1a, the BBCEAS optical system consists of a laser-driven arc lamp, collimating optics, optical filters, cavity, and grating spectrometer with charge-coupled device (CCD) array detector. This is similar to the laboratory instrument described previously (Washenfelder et al., 2008; Axson et al., 2011; Kahan et al., 2012), although the light source, collimating optics, optical filters, and grating spectrometer have been replaced to optimize measurements from 315 to $350 \mathrm{~nm}$.

We use a broadband light source (EQ-99FC LDLS; Energetiq, Woburn, MA, USA), consisting of a continuous-wave diode laser at $974 \mathrm{~nm}$ that pumps a Xenon plasma (Islam et al., 2013) with a total electrical power draw of $125 \mathrm{~W}$. The resulting plasma size is less than $100 \times 200 \mu \mathrm{m}$, with spectral output from 170 to $2100 \mathrm{~nm}$. Further details about laserdriven arc lamps and a comparison to conventional Xenon arc lamps can be found in Zhu and Blackborow (2011). The light source is air-cooled, but temperature drift caused the output intensity to vary as much as $10 \%$ in $1 \mathrm{~h}$. To eliminate this drift, we constructed custom temperature control using water circulation through an attached aluminum plate. Change in lamp intensity as a function of wavelength is an additional consideration, and we measured the relative intensity change over $315-350 \mathrm{~nm}$ to be less than $0.3 \%$ in $1 \mathrm{~h}$. The light source is purged with a continuous flow of $\mathrm{N}_{2}$ gas to eliminate ozone production in the lamp housing. Inside the housing, the light is collected using an ellipsoidal reflector and a $600 \mu \mathrm{m}$ diameter fiber, resulting in a manufacturer-specified power output of $130 \mu \mathrm{W} \mathrm{nm}{ }^{-1}$ across the $315-350 \mathrm{~nm}$ spectral region. This light is collimated and coupled into the cavity using an offaxis parabola with 0.36 numerical aperture (RC04SMA-F01; Thorlabs, Newton, NJ, USA). Prior to entering the cavity, the light passes through two colored glass filters (Schott Glass WG320 and UG11).

The optical cavity is formed by two $2.5 \mathrm{~cm}$ diameter, $1 \mathrm{~m}$ radius of curvature mirrors (Layertec $\mathrm{GmbH}$, Mellingen, Germany), with manufacturer reported reflectivity of $0.9995(1-$ reflectivity $=500 \mathrm{ppm}$ loss$)$ at their nominal center wavelength of $330 \mathrm{~nm}$. The mirrors were mounted at either end of a $100 \mathrm{~cm}$ long Teflon cell $(2.5 \mathrm{~cm}$ outside diameter), with gas ports for input, output, and mirror purge flows. The optical cavity is mechanically stabilized using $2 \mathrm{~cm}$ diameter carbon fiber rods and custom optical mounts. The light exiting the cavity is imaged by a $2.54 \mathrm{~cm}$ diameter $\mathrm{F} / 3.1$ lens onto a $0.5 \mathrm{~cm}$ F/2 lens (74-UV; Ocean Optics, Dunedin, FL, USA) that couples the light into one lead of a custom fiber bundle. There is an additional shortpass filter to eliminate stray light (XUS0350; Asahi Spectra USA, Inc., Torrance, CA, USA). 
The optical fiber bundle consists of two leads, with seven $200 \mu \mathrm{m}$ diameter fibers each. These are arranged linearly along the input slit axis of the grating spectrometer, with each lead illuminating a separate region of the CCD. Spectra were acquired using a $203 \mathrm{~mm}$ focal length grating spectrometer (IsoPlane-160; Princeton Instruments, Trenton, NJ, USA) with an internal shutter, tunable grating, and manual entrance slit. The astigmatism of the IsoPlane-160 is less than $100 \mu \mathrm{m}$ over the $26 \mathrm{~mm}$ wide focal plane. During these experiments, we used a 1200 line $\mathrm{mm}^{-1}$ grating (300 nm blaze) and a $100 \mu \mathrm{m}$ entrance slit width. The CCD array is a 16 bit, backilluminated detector with $2048 \times 512$ pixels (PIXIS $2 \mathrm{kBUV}$; Princeton Instruments, Trenton, NJ, USA), which is thermoelectrically cooled to $-70^{\circ} \mathrm{C}$ to reduce thermal noise. The PIXIS 2kBUV had negligible time-dependent thermal noise, and its dark background was dominated by the offset voltage and readout noise.

The two regions of the CCD were used to measure the light output by the laser-driven arc lamp and the intensity through the optical cavity, as shown in Fig. 1. This allowed monitoring for drift in the light intensity. Unlike in previous experiments, the signal from each region was not accumulated in hardware to generate two spectra. Instead, the signal for the entire CCD was read out and the two regions were summed in software, which allowed for greater integration times and protected the shutter assembly from overheating by reducing its operation frequency. Individual spectra were acquired with 1.2 or $2.0 \mathrm{~s}$ integration time, and averaged for a total data acquisition time of $30 \mathrm{~s}$ or $1 \mathrm{~min}$.

The IsoPlane grating position was set to a center wavelength of $330 \mathrm{~nm}$ with $103 \mathrm{~nm}$ bandwidth. The optical resolution was determined by fitting narrow emission lines from a $\mathrm{Hg} / \mathrm{Ar}$ lamp. The observed line shape was nearly Gaussian with a full width at half maximum (FWHM) of $0.47 \mathrm{~nm}$ at $330 \mathrm{~nm}$.

\subsection{Cavity ring-down spectrometer for $\mathrm{NO}_{2}$ validation}

Concentrations of $\mathrm{NO}_{2}$ were independently measured using cavity ring-down spectroscopy at $406.4 \mathrm{~nm}$, as described previously (Washenfelder et al., 2008; Fuchs et al., 2009). Briefly, a continuous-wave diode laser is modulated at $1.6 \mathrm{kHz}$ and coupled into a high finesse cavity. The output light is measured with a photomultiplier tube and recorded with a data acquisition card. Measurements of the laser line shape showed that it was centered at $406.4 \mathrm{~nm}$ and was approximately Gaussian with FWHM of $0.48 \mathrm{~nm}$. The laser line shape was convolved with a high-resolution $\mathrm{NO}_{2}$ reference cross section (Vandaele et al., 1998).

\subsection{Preparation and delivery of $\mathrm{CH}_{2} \mathrm{O}$ and $\mathrm{NO}_{2}$}

Formaldehyde was prepared by purification of paraformaldehyde, following the general method described in Meller and Moortgat (2000). Paraformaldehyde was gently heated in a glass tube connected to a vacuum system. Water from the paraformaldehyde decomposition was trapped in a cold finger, while formaldehyde was collected in a $12 \mathrm{~L}$ glass bulb. The bulb was subsequently diluted with $\mathrm{N}_{2}$, for a final concentration of $1-2$ ppmv $\mathrm{CH}_{2} \mathrm{O}$ in $\mathrm{N}_{2}$. Because formaldehyde readily polymerizes at high concentrations (Meller and Moortgat, 2000), the diluted formaldehyde sample was stored in dark conditions at room temperature. Nitrogen dioxide was prepared by flow dilution from a standard cylinder containing 15.8 ppmv $\mathrm{NO}_{2}$ in $\mathrm{N}_{2}$ (Scott-Marrin, Inc., Riverside, CA, USA).

The experimental flow system is shown in Fig. 1b. The BBCEAS and CRDS instruments were connected in series. Prior measurements under dry conditions have shown negligible losses to Teflon and metal surfaces for $\mathrm{NO}_{2}$ (Fuchs et al., 2009) and glyoxal (a dialdehyde with greater Henry's Law constant than formaldehyde; Washenfelder et al., 2008; Min et al., 2015). A study of formaldehyde sampling artifacts similarly concluded it is relatively inert to adsorption by Teflon (Wert et al., 2002). Pressure (626A; MKS Instruments, Andover, MA, USA) and temperature (K-type thermocouple; Omega Engineering, Inc., Stamford, CT, USA) were monitored at the exit of the CRDS cavity and used to calculate number density for the BBCEAS and CRDS. Over the experimental concentration range, $\mathrm{CH}_{2} \mathrm{O}$ and $\mathrm{NO}_{2}$ did not measurably affect mirror cleanliness or reflectivity, so mirror purges were not used for the BBCEAS instrument. Mirror purges were necessary for the CRDS due to its existing cell design. Typical flows of 2.0 standard $\mathrm{L} \mathrm{min}^{-1}$ (slpm) of zero air; 0-20 standard $\mathrm{cm}^{3} \mathrm{~min}^{-1}$ ( $\mathrm{sccm}$ ) of $15.8 \mathrm{ppmv}$ $\mathrm{NO}_{2}$; and $0-40 \mathrm{sccm}$ of $1-2$ ppmv $\mathrm{CH}_{2} \mathrm{O}$ were introduced to the cells and allowed to exhaust to ambient atmospheric pressure.

\subsection{Operation}

During normal laboratory operation, the BBCEAS and CRDS were turned on at least $2 \mathrm{~h}$ prior to beginning measurements. This allowed sufficient time for the laser-driven arc lamp and its temperature to stabilize. The required warm up time could be reduced in the future with improved temperature control. Dark spectra were acquired with identical integration time $(1.2$ or $2.0 \mathrm{~s})$ as the sample spectra and 510 dark spectra were averaged together. The total acquisition time for each sample spectrum was $1 \mathrm{~min}$, which included the shutter compensation and CCD readout time, allowing 35 spectra with $1.2 \mathrm{~s}$ integration time to be acquired in $1 \mathrm{~min}$ (equivalent to a duty cycle of $70 \%$ ). This duty cycle does not include the intermittent measurement of dark spectra. $\mathrm{He}$ and $\mathrm{N}_{2}$ spectra were measured for 1 min each to calculate the mirror reflectivity of the BBCEAS channel. During standard additions, reflectivity measurements were repeated at 15-20 min intervals, and zero air measurements were repeated between each standard addition. 


\section{Data analysis}

\subsection{Determination of mirror reflectivity and extinction}

Extinction in a BBCEAS cavity can be described using an infinite sum for the light transmission through the cavity (Fiedler et al., 2003) or a differential equation for light input and output (Washenfelder et al., 2008). These two approaches give an equivalent expression that relates the optical extinction, $\alpha(\lambda)$, to the observed change in transmitted light intensity through the cavity. If we define the reference spectrum as a cavity filled with zero air, the expression is

$\alpha(\lambda)=\left(\frac{1-R(\lambda)}{d}+(\lambda)_{\text {Rayleigh, } \mathrm{ZA}}\right)\left(\frac{I_{\mathrm{ZA}}(\lambda)-I(\lambda)}{I(\lambda)}\right)$,

where $\lambda$ is the wavelength of light, $d$ is the cavity length,

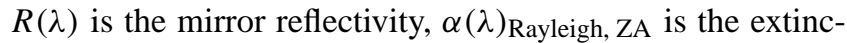
tion due to Rayleigh scattering of zero air, $I_{\mathrm{ZA}}(\lambda)$ is the reference spectrum, and $I(\lambda)$ is the measured spectrum at each wavelength. If mirror purge volumes were included, the right-hand side of Eq. (1) would require a multiplicative factor equal to $d / L$, where $L$ is the length over which the absorbing sample is present. Eliminating the mirror purges in the laboratory instrument described here eliminates a source of uncertainty.

Calculating extinction from Eq. (1) requires knowledge of the mirror reflectivity, $R(\lambda)$. This can be determined by introducing a well-known extinction into the cavity. Rayleigh scattering is convenient because it varies slowly with wavelength across the entire region of interest, and requires only measurements of temperature and pressure. Here, we use measurements of the Rayleigh extinction for helium and zero air to calculate $R(\lambda)$. Based on the recommendation of Thalman et al. (2014), we have used theoretical Rayleigh scattering cross sections from Sneep and Ubachs (2005; see Eqs. 11, 12, 23, and 24) for $\mathrm{N}_{2}$ and $\mathrm{O}_{2}$. The Rayleigh scattering cross section for $\mathrm{He}$ is based on an empirical fit to measurements by Shardanand and Rao (1977), $\sigma_{\text {Rayleigh, } \mathrm{He}}=$ $1.336 \times 10^{-17} \times \lambda^{-4.1287}$. Because the mirror reflectivity is calibrated using well-known Rayleigh scattering cross sections (uncertainty $\pm 4 \%$ in the UV), the derived trace gas absorption or aerosol extinction retains high accuracy, similar to conventional direct absorption or extinction instruments.

\subsection{Spectral retrieval method}

The measured extinction in Eq. (1) contains contributions from each of the absorbers in the cavity:

$$
\begin{aligned}
\alpha(\lambda) & =\sum_{i}^{n} \alpha_{i}(\lambda)=\sum_{i}^{n} \sigma_{i}(\lambda) N_{i} \\
& =\sigma_{\mathrm{CH}_{2} \mathrm{O}}(\lambda)\left[\mathrm{CH}_{2} \mathrm{O}\right]+\sigma_{\mathrm{NO}_{2}}(\lambda)\left[\mathrm{NO}_{2}\right]+\ldots,
\end{aligned}
$$

where $n$ is the number of absorbers, $\sigma_{i}(\lambda)$ is the absorption cross section, and $N_{i}$ is the number density of the $i$ th absorber. The number density of each absorber can be determined from the measured extinction, $\alpha(\lambda)$, and reference spectra for each absorber, $\sigma_{i}(\lambda)$.

For the spectral retrievals, reference spectra for $\mathrm{CH}_{2} \mathrm{O}$ (Meller and Moortgat, 2000) and $\mathrm{NO}_{2}$ (Vandaele et al., 1998) were convolved with a Gaussian line shape with FWHM $0.47 \mathrm{~nm}$. These reference spectra were used with DOAS Intelligent System (DOASIS) spectral fitting software (Kraus, 2006) to retrieve number densities of $\mathrm{CH}_{2} \mathrm{O}$ and $\mathrm{NO}_{2}$. The spectra were fit from 315 to $350 \mathrm{~nm}$, and a fourth-order polynomial was included in each fit to account for drift in the light intensity and cavity throughput.

\section{Results and discussion}

\subsection{Measured spectra and calculated mirror reflectivity}

Figure 2a shows spectra obtained with the absorption cell filled with $\mathrm{He}$ and zero air for 24 spectra with $2.0 \mathrm{~s}$ integration time. The spectral intensity is determined by the product of the laser-driven arc lamp spectrum (170-2100 nm), the three optical filters, and the transmission of the cavity mirrors. The intensity is lower near $330-340 \mathrm{~nm}$ where the mirror reflectivity is higher and the mirror transmission is lower. The accumulated counts at $330 \mathrm{~nm}$ were approximately $4.3 \times$ $10^{6}$ in $2.0 \mathrm{~s}$. Figure $2 \mathrm{~b}$ shows the mirror reflectivity calculated from Eq. (1). The peak reflectivity is $0.99930 \pm 0.00003$ (700 ppm loss) at $338 \mathrm{~nm}$ and $0.99922 \pm 0.00004$ at $330 \mathrm{~nm}$. This is slightly lower than the manufacturer's specifications of 0.9995 at $330 \mathrm{~nm}$. The repeatability of this result, even after standard procedures for careful mirror cleaning, suggests that it does not arise from surface deposits on the mirrors. This discrepancy has been reported previously for BBCEAS instruments and has been attributed to photons propagating off-axis in the cavity or populating very high-order transverse modes with greater losses than lower-order modes (Varma et al., 2009).

For a $100 \mathrm{~cm}$ cavity containing $830 \mathrm{hPa}$ of zero air with $R=99.930 \%$ mirrors at $338 \mathrm{~nm}$, the per pass fractional losses are $700 \mathrm{ppm}$ mirror loss and $73 \mathrm{ppm}$ Rayleigh scattering loss. The measured transmission through a single mirror is $210 \mathrm{ppm}$ at $338 \mathrm{~nm}$, indicating that absorption and scattering are $490 \mathrm{ppm}$ and dominate the losses in the cavity. This 

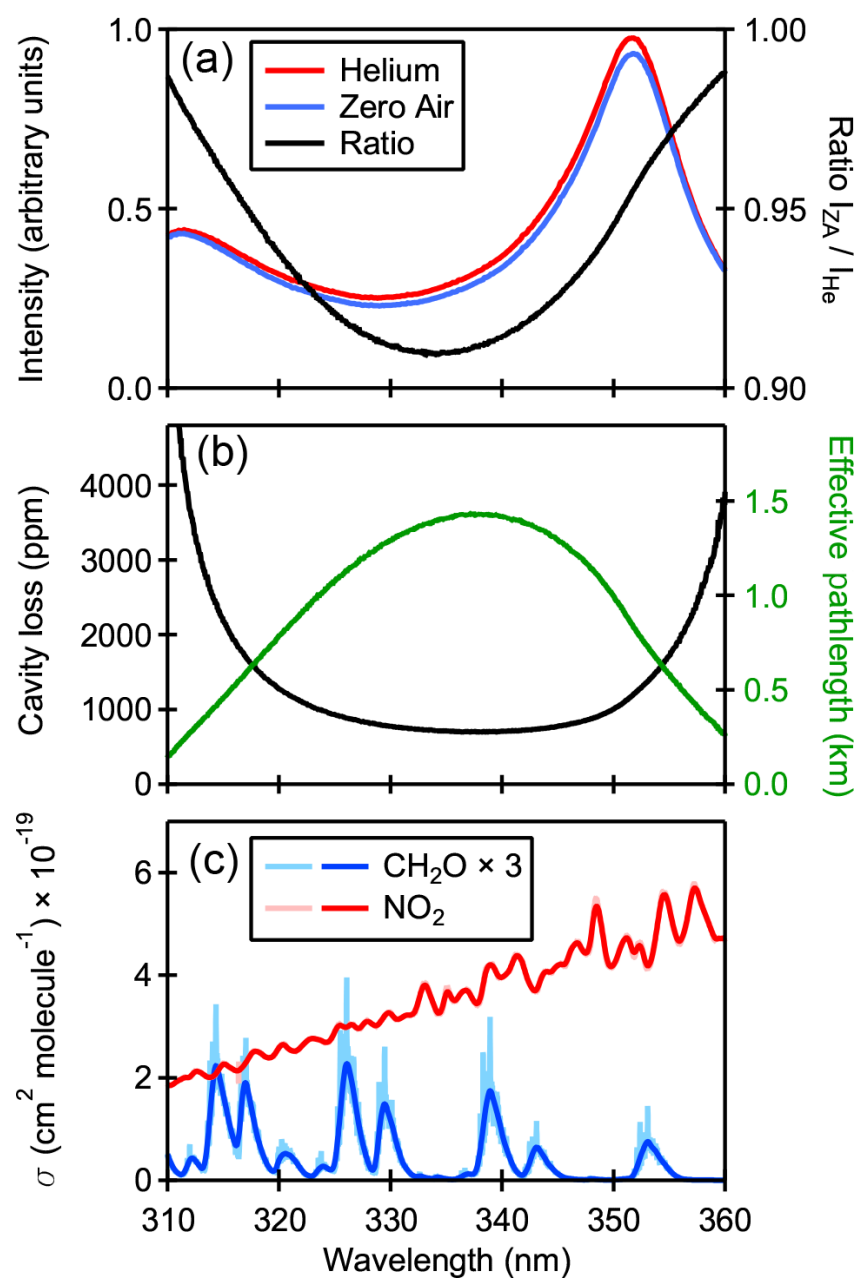

Figure 2. (a) Spectral measurements of $I_{\mathrm{He}}$ and $I_{\mathrm{ZA}}$, and the ratio of $I_{\mathrm{ZA}} / I_{\mathrm{He}}$. (b) Cavity loss, $1-R(\lambda)$, and effective pathlength, $d /(1-R(\lambda))$, determined from the Rayleigh extinction of He and zero air spectra, as described in the text. (c) Reference spectra for $\mathrm{CH}_{2} \mathrm{O}$ (light blue; Meller and Moortgat, 2000) and $\mathrm{NO}_{2}$ (light red; Vandaele et al., 1998) convolved with a Gaussian lineshape with FWHM $0.47 \mathrm{~nm}\left(\mathrm{CH}_{2} \mathrm{O}\right.$ dark blue; $\mathrm{NO}_{2}$ dark red $)$. The $\mathrm{CH}_{2} \mathrm{O}$ cross sections have been multiplied by three to put them on the same scale with those of $\mathrm{NO}_{2}$.

contrasts sharply with higher quality mirrors available in the visible spectral region, where cavity measurements at $455 \mathrm{~nm}$ have demonstrated 34 ppm mirror loss and $19 \mathrm{ppm}$ Rayleigh scattering (Washenfelder et al., 2008).

\subsection{Measurements of $\mathrm{NO}_{2}$}

Using the flow system shown in Fig. 1b, standard additions of $\mathrm{NO}_{2}$ diluted with zero air were introduced to the BBCEAS and CRDS instruments in series. The calculated extinction for different $\mathrm{NO}_{2}$ concentrations, with fits determined by DOASIS spectral fitting, are shown in Fig. 3, with fitting residuals shown in the upper panel. The average fit uncertainty is 360 pptv $\mathrm{NO}_{2}$ in $1 \mathrm{~min}$.

We note that the differential absorption features for $\mathrm{NO}_{2}$ are weaker in this spectral region compared to the visible region of the spectrum. For example, the maximum differential $\mathrm{NO}_{2}$ cross section in this region is $24.7 \%$ of the absolute extinction at $348.5 \mathrm{~nm}$ (spectral resolution $0.47 \mathrm{~nm}$ ). In contrast, the differential cross section is $54.0 \%$ of the absolute extinction at $448.1 \mathrm{~nm}$, and our previous measurements at $440-470 \mathrm{~nm}$ demonstrate a detection sensitivity $(1 \sigma)$ of 40 pptv in $5 \mathrm{~s}$ (Washenfelder, 2008, 2011; Min et al., 2015). Part of this difference is due to the spectrally intense LED light source and lower loss mirrors, but part is also due to the larger differential $\mathrm{NO}_{2}$ cross section in the visible spectral region.

The correlation plot of the independent $\mathrm{NO}_{2}$ measurements is shown in Fig. 4. The slope is $1.024 \pm 0.027$ and the intercept is $-0.20 \pm 0.32 \mathrm{ppb}$, with $r^{2}=0.998$. Despite the weaker differential absorption features, the ultraviolet BBCEAS instrument accurately quantifies the $\mathrm{NO}_{2}$ concentrations relative to the more precise CRDS instrument and is within the combined uncertainty of the Rayleigh scattering mirror reflectivity calibration and the $\mathrm{NO}_{2}$ absorption cross section $( \pm 5.1 \%$; see Sect. 4.5$)$.

\subsection{Measurements of $\mathrm{CH}_{2} \mathrm{O}$}

The calculated extinction for different $\mathrm{CH}_{2} \mathrm{O}$ concentrations, with fits determined by DOASIS, are shown in Fig. 5 with fitting residuals in the upper panel. The average fit uncertainty is 400 pptv $\mathrm{CH}_{2} \mathrm{O}$ in $1 \mathrm{~min}$. The maximum absolute absorption cross section of $\mathrm{CH}_{2} \mathrm{O}$ at this resolution is $7.6 \times 10^{-20} \mathrm{~cm}^{2}$ molecule ${ }^{-1}$ at $326.0 \mathrm{~nm}$. $\mathrm{CH}_{2} \mathrm{O}$ is a relatively weak absorber compared to other species, such as glyoxal, whose peak cross section at $455 \mathrm{~nm}$ is 7 times greater. The weak absolute cross section of $\mathrm{CH}_{2} \mathrm{O}$ makes it one of the more challenging UV absorbers to retrieve, despite its strong differential absorption in the ultraviolet spectral region, where the differential cross section is $91.0 \%$ of the absolute extinction at $326.0 \mathrm{~nm}$.

The correlation plot for $\mathrm{CH}_{2} \mathrm{O}$ is shown in Fig. 6. In this case, $\mathrm{CH}_{2} \mathrm{O}$ is compared to a scaled concentration based on flow dilution, rather than to an independent measurement, because the $\mathrm{CH}_{2} \mathrm{O}$ concentration in the bulb is not known accurately. For this comparison, $r^{2}=0.9998$.

\subsection{Simultaneous measurements of $\mathrm{NO}_{2}$ and $\mathrm{CH}_{2} \mathrm{O}$}

The dominant ambient lower atmospheric absorbers in this spectra region are $\mathrm{NO}_{2}$ and $\mathrm{CH}_{2} \mathrm{O}$, and ambient samples will likely contain a mixture of both. We introduced mixtures of these two species to the BBCEAS and CRDS cells using the flow system shown in Fig. 1b. A time series with the sequential introduction of $9.7 \mathrm{ppbv} \mathrm{NO}_{2}, 15.6 \mathrm{ppbv} \mathrm{CH}_{2} \mathrm{O}$, $5.5 \mathrm{ppbv} \mathrm{NO}_{2}$, and $7.5 \mathrm{ppbv} \mathrm{CH}_{2} \mathrm{O}$ is shown in Fig. 7. Each 


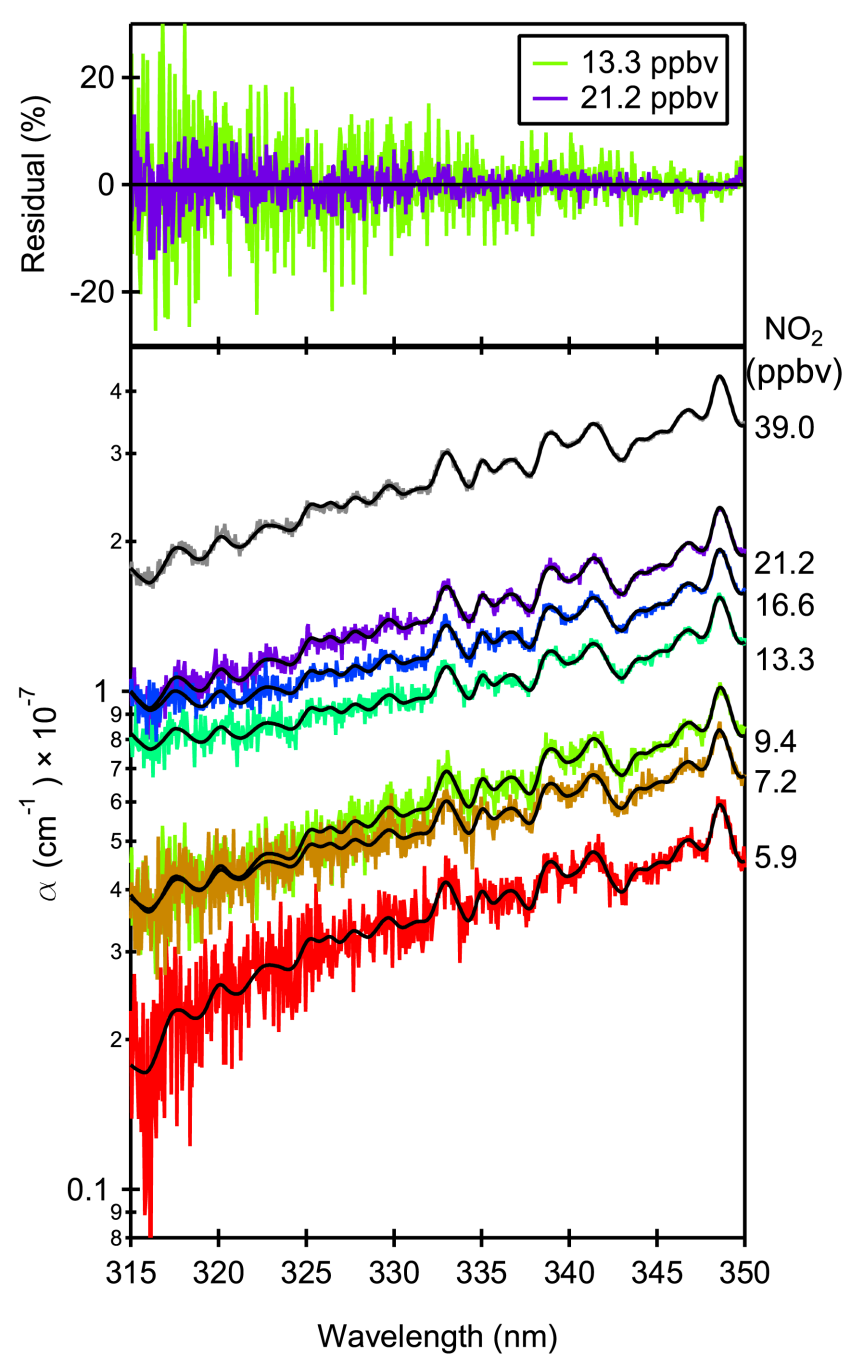

Figure 3. Measured $\alpha(\lambda)$ for $1 \mathrm{~min}$ standard additions and calculated spectral fits for seven $\mathrm{NO}_{2}$ concentrations from 6 to $39 \mathrm{ppbv}$. Two fitting residuals are shown in the upper panel. The average fit uncertainty for all concentrations shown is $360 \mathrm{pptv} \mathrm{NO}_{2}$.

point represents the average of 17 spectra with $1.2 \mathrm{~s}$ integration time ( $30 \mathrm{~s}$ total acquisition time). The decrease in the measured $\mathrm{CH}_{2} \mathrm{O}$ concentration during the first addition is due to drift in the output from the pressurized $\mathrm{CH}_{2} \mathrm{O}$ bulb. During the second set of additions, the $1 \sigma$ standard deviations for $\mathrm{NO}_{2}$ and $\mathrm{CH}_{2} \mathrm{O}$ are 140 and 210 pptv, respectively. This represents the detection limit and experimental precision for these measurements. Increasing the averaging time to $10 \mathrm{~min}$ would improve the detection limits for $\mathrm{NO}_{2}$ and $\mathrm{CH}_{2} \mathrm{O}$ to 30 and $50 \mathrm{pptv}$, respectively, assuming that the averaging follows the square root of the number of points. Experience from prior ground-based field measurements of glyoxal and nitrous acid showed that their measurement precision scaled linearly with the square root of averaging time over 10-60 min periods, when zeros were acquired at more

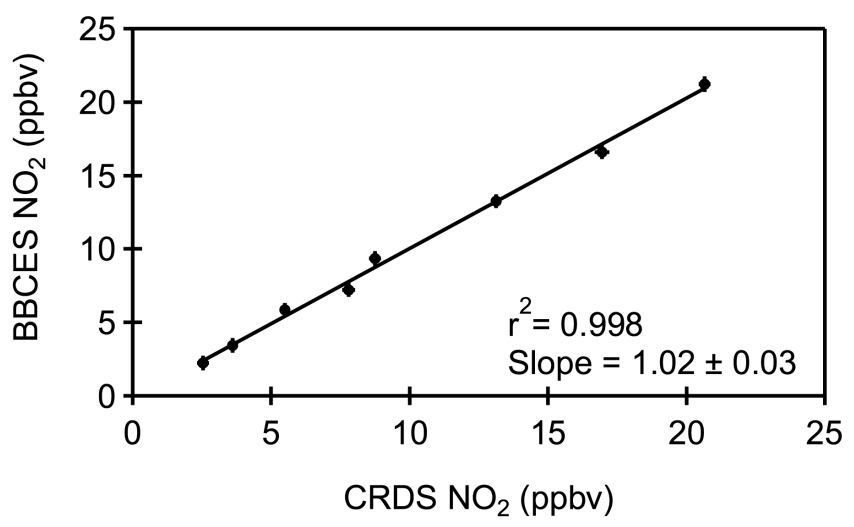

Figure 4. Correlation plot comparing $\mathrm{NO}_{2}$ measurements from the BBCEAS and CRDS instruments during 1 min standard additions. The slope is $1.024 \pm 0.027$ with intercept of $-0.20 \pm 0.32 \mathrm{ppbv}$ (black line) and $r^{2}=0.998$.

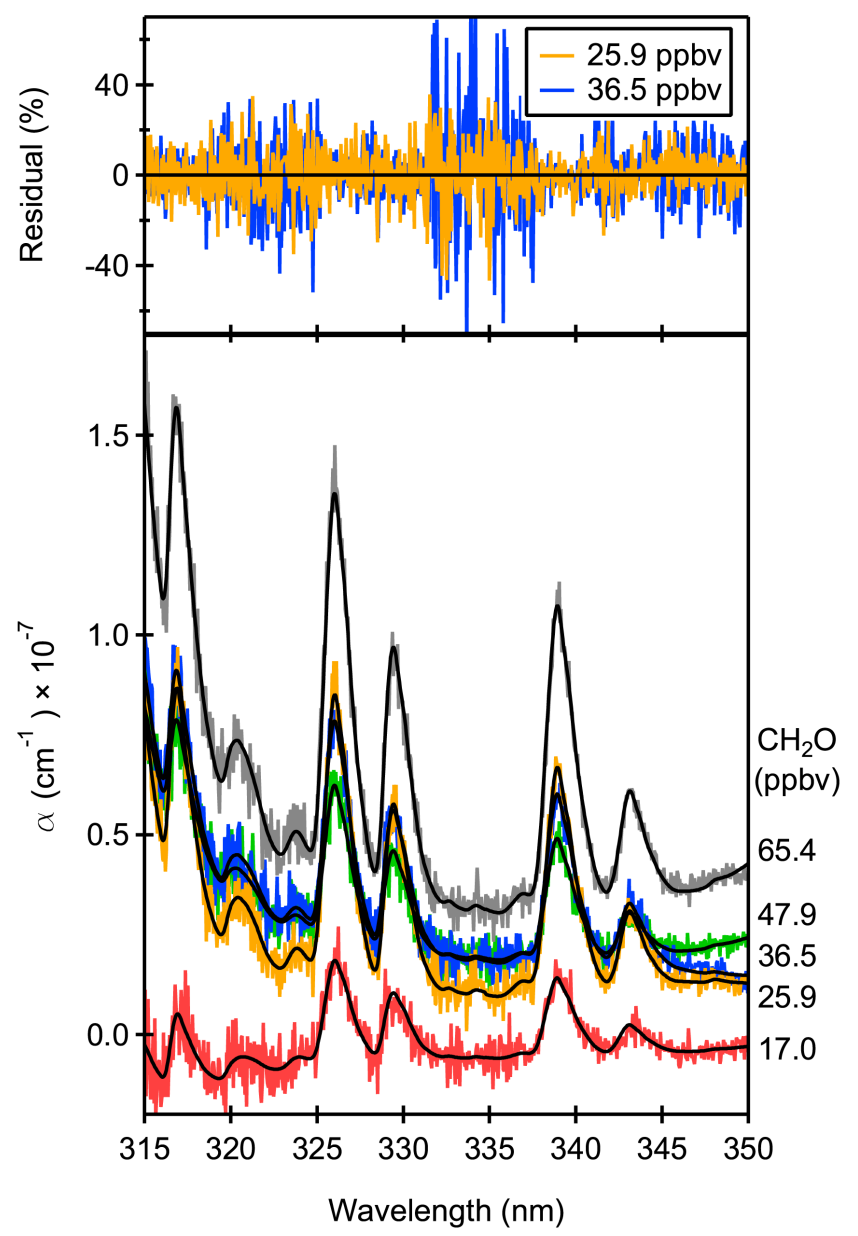

Figure 5. Measured $\alpha(\lambda)$ and calculated spectral fits for $\mathrm{CH}_{2} \mathrm{O}$ concentrations from 17 to 65 ppbv. Two fit residuals are shown in the upper panel. The average fit uncertainty for all concentrations shown is 400 pptv $\mathrm{CH}_{2} \mathrm{O}$. 


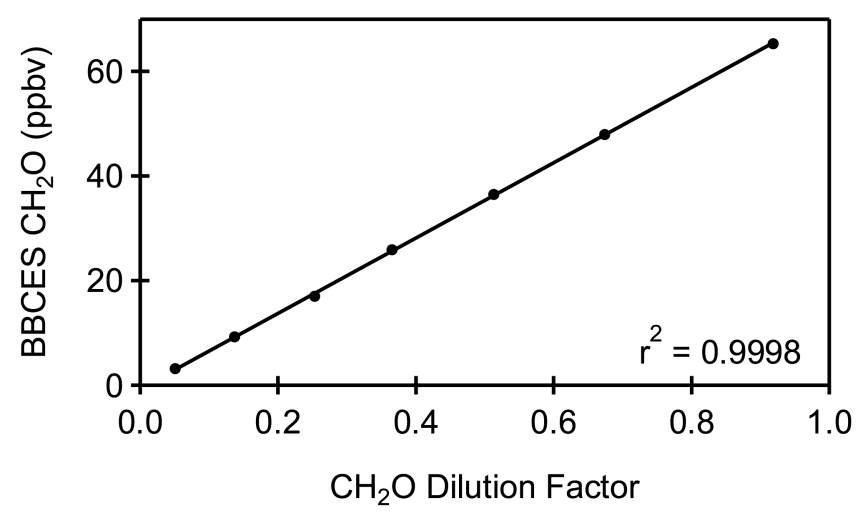

Figure 6. Correlation plot comparing $\mathrm{CH}_{2} \mathrm{O}$ measurements from the BBCEAS with the dilution scaling during 1 min standard additions. The absolute $\mathrm{CH}_{2} \mathrm{O}$ concentration is not well known, so the slope is not calculated. The $r^{2}$ value is 0.9998 and intercept is $-0.6 \pm 0.2 \mathrm{ppbv}$.

frequent intervals (Washenfelder et al., 2011; Young et al., 2012).

\subsection{Precision and accuracy of the $\mathrm{NO}_{2}$ and $\mathrm{CH}_{2} \mathrm{O}$ measurements}

An examination of Eq. (1) shows that the precision for extinction, $\alpha(\lambda)_{\min }$, depends on the smallest measurable difference in light through the cavity, $\delta I_{\min }(\lambda)$, which is equal to $\left(\frac{\left(I_{\mathrm{ZA}}(\lambda)-I(\lambda)\right)}{I(\lambda)}\right)_{\min }$.

$\alpha_{\min }(\lambda)=\left(\frac{1-R(\lambda)}{d}+(\lambda)_{\text {Rayleigh }}\right) \delta I_{\min }(\lambda)$

For cavity mirrors with lower reflectivity, $R(\lambda)$, a smaller value for $\delta I_{\min }(\lambda)$ is required to achieve the same detection limit. As the effective path length becomes shorter, it is necessary to accurately detect increasingly small changes in intensity, and the drift of the light source and cavity alignment can become limiting factors in the precision. Conversely, lower reflectivity mirrors may have larger transmission of the light source (depending on the balance between transmission, absorption, and scattering in the mirror coating), increasing the photon count rate and thus the precision of $\delta I_{\min }$ if the system is shot noise limited. Based on the acquired counts of $1.0 \times 10^{8}$ in $1 \mathrm{~min}$, the calculated $1 \sigma \alpha_{\min }$ at $330 \mathrm{~nm}$ would be $7.4 \times 10^{-10} \mathrm{~cm}^{-1}$ in the shot noise limit. However, achieving this theoretical value requires a strict cavity stability, with $\delta I_{\min }=1.0 \times 10^{-4}$. Figure 8 shows an Allan deviation plot (Allan, 1966) calculated for a $3 \mathrm{~h}$ series of spectra, with a minimum of $5 \times 10^{-9} \mathrm{~cm}^{-1}$ for $9 \mathrm{~s}$ and $6 \times 10^{-9} \mathrm{~cm}^{-1}$ for $1 \mathrm{~min}$. Temperature-controlling and purging the laser-driven arc lamp have reduced the intensity drift, but Fig. 8 shows that frequent zeroing will be useful to improve measurement precision.
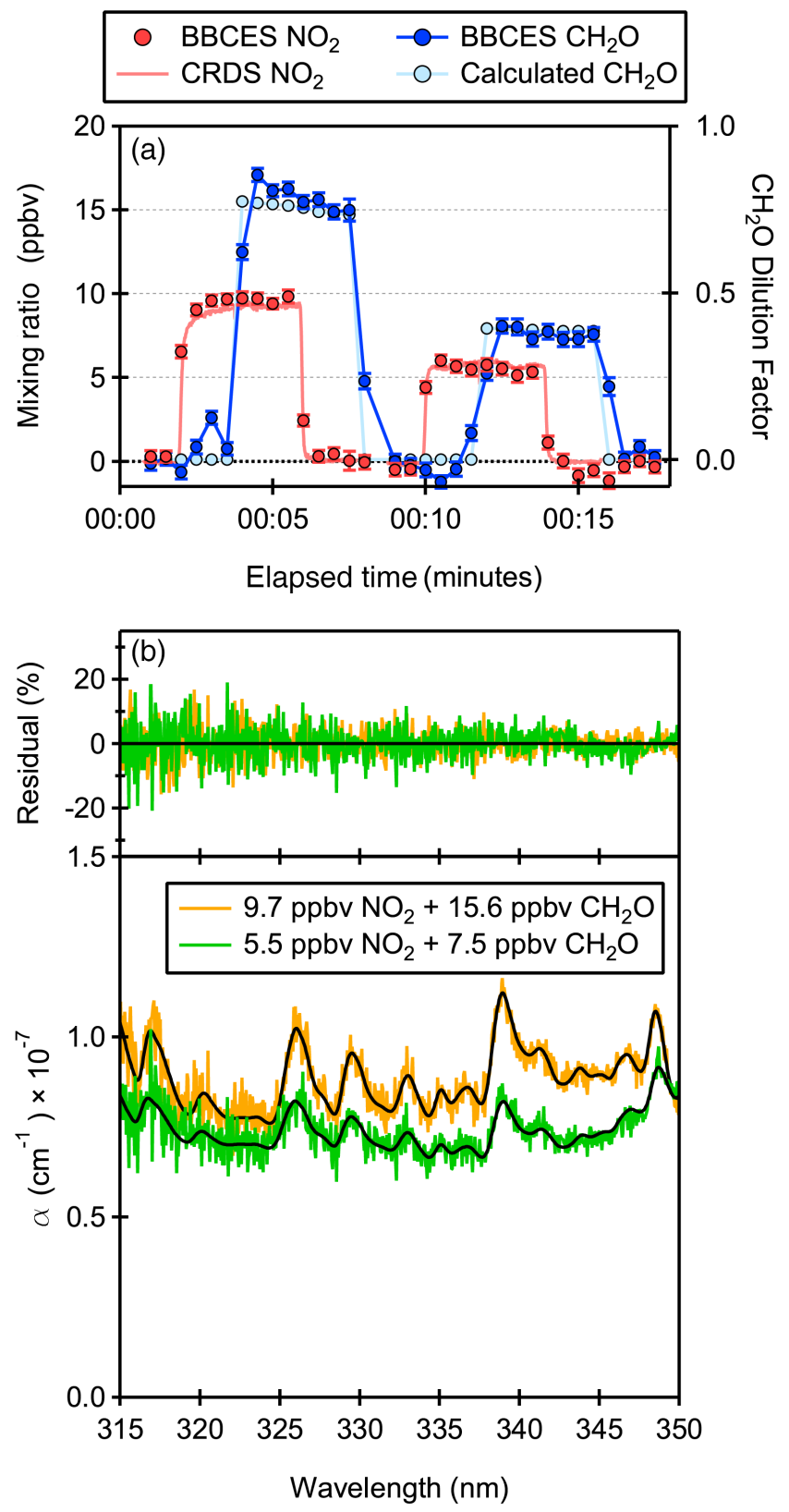

Figure 7. (a) Time series of $30 \mathrm{~s}$ measurements of sequential additions of 9.7 ppbv $\mathrm{NO}_{2}, 15.6 \mathrm{CH}_{2} \mathrm{O}, 5.5 \mathrm{ppbv} \mathrm{NO}_{2}$, and $7.5 \mathrm{CH}_{2} \mathrm{O}$ during a 17 min period. $\mathrm{BBCEAS} \mathrm{NO}_{2}$ and $\mathrm{CH}_{2} \mathrm{O}$ concentrations are compared to CRDS $\mathrm{NO}_{2}$ concentrations and calculated $\mathrm{CH}_{2} \mathrm{O}$ dilution factors. (b) Measured $\alpha(\lambda)$ and calculated spectral fits for 30 s measurements with different $\mathrm{CH}_{2} \mathrm{O}$ and $\mathrm{NO}_{2}$ concentrations.

The absolute accuracy depends on the accuracy of the Rayleigh scattering cross section for zero air $( \pm 4 \%)$, Rayleigh scattering cross section for helium (negligible contribution), absorption cross section for $\mathrm{NO}_{2}( \pm 3 \%$; Vandaele et al., 1998), absorption cross section for $\mathrm{CH}_{2} \mathrm{O}( \pm 5 \%$; Meller and Moortgat, 2000), sample pressure $( \pm 0.5 \%)$, and temperature $( \pm 0.7 \%)$. Summed in quadrature, the to- 


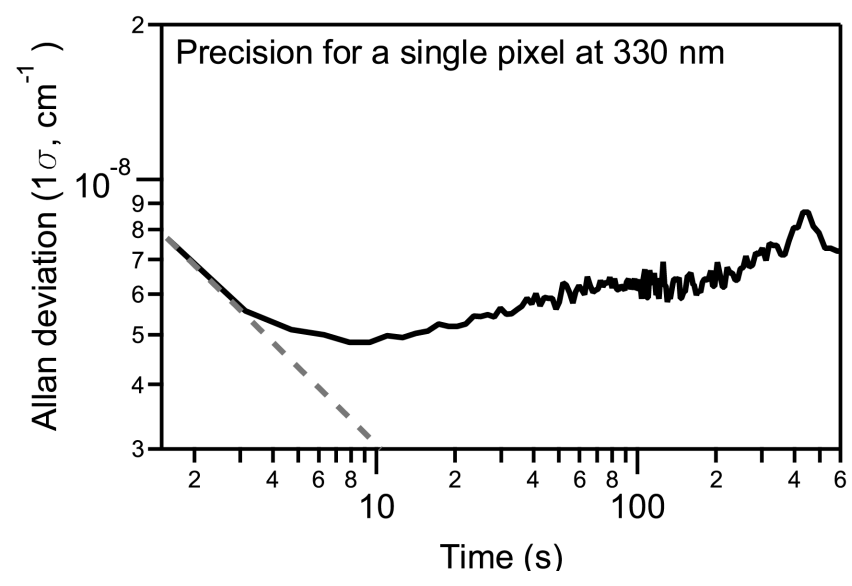

Figure 8. Allan deviation plot for zero air measurements acquired by the BBCEAS instrument, showing the relationship between averaging time and $1 \sigma$ precision for a single pixel at $330 \mathrm{~nm}$. The dashed line shows the relationship expected for statistically random noise.

tal calculated uncertainty is $5.1 \%$ for $\mathrm{NO}_{2}$ and $6.5 \%$ for $\mathrm{CH}_{2} \mathrm{O}$. This expected measurement accuracy is consistent with the comparison of the $\mathrm{NO}_{2}$ retrievals from the ultraviolet BBCEAS instrument to the $405 \mathrm{~nm}$ CRDS instrument.

\section{Summary and conclusions}

With a $2 \sigma$ detection limit of 300 pptv $\mathrm{CH}_{2} \mathrm{O}$ in $1 \mathrm{~min}$, the current demonstration of this measurement technique is appropriate for laboratory studies of $\mathrm{CH}_{2} \mathrm{O}$, ground-based field measurements in regions with high $\mathrm{CH}_{2} \mathrm{O}$ mixing ratios (for example, regions with large emissions and rapid oxidation of anthropogenic or biogenic VOCs), and ground-based field measurements of cleaner environments with increased averaging time ( $>5 \mathrm{~min})$.

Although the current precision is not competitive with the best spectroscopic in situ $\mathrm{CH}_{2} \mathrm{O}$ instruments, the ultraviolet BBCEAS is comparable to current ground- and satellitebased DOAS instruments, which use signal averaging to achieve lower detection limits. State-of-the-art DOAS instruments report $\mathrm{CH}_{2} \mathrm{O}$ detection limits of approximately $150 \mathrm{pptv}$ for data acquisition times of 5-10 min (Warneke et al., 2011), while $\mathrm{CH}_{2} \mathrm{O}$ satellite data are typically analyzed as monthly or seasonal averages (Chance et al., 2000; Wittrock et al., 2006). With signal averaging, the ultraviolet BBCEAS could be competitive with these direct absorption instruments, while providing a true in situ measurement. Previous work has shown that it is possible to construct inlets for formaldehyde that have minimal sampling artifacts (Wert et al., 2002). The BBCEAS method may also be useful as a lower-time-resolution validation for wet chemical, mass spectrometry, and fluorescence methods, because it is essen-

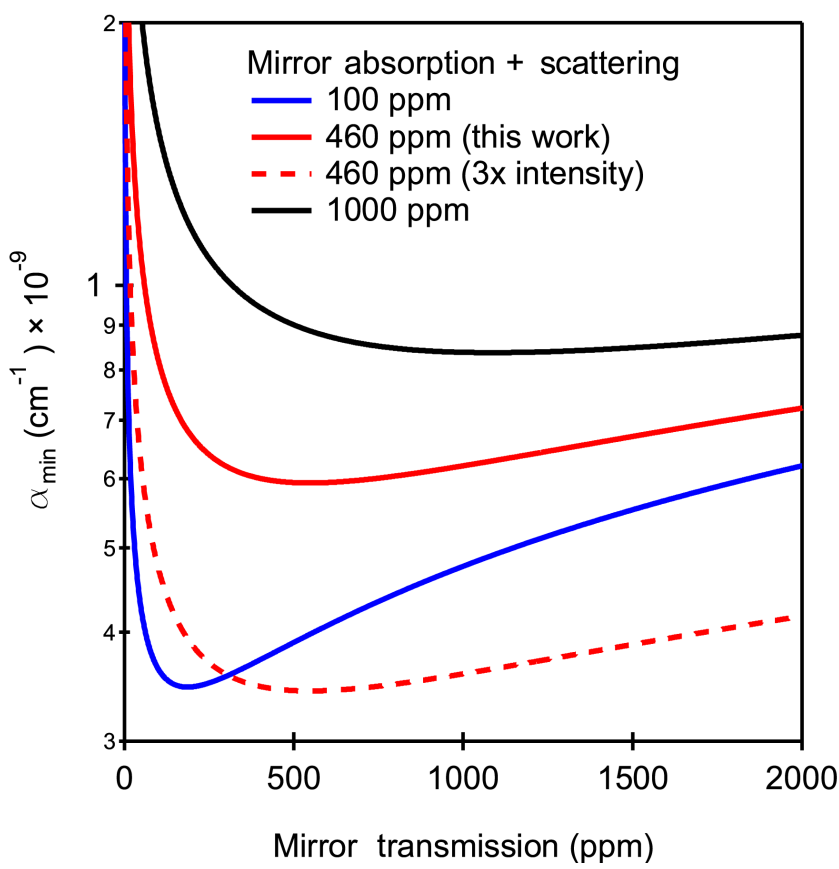

Figure 9. Calculated relationship between $\alpha_{\min }$, mirror transmission, and the sum of mirror absorption and scattering at $330 \mathrm{~nm}$, following Eq. (3) and assuming shot noise limited performance. The current mirrors have absorption and scattering losses of $460 \mathrm{ppm}$ and transmission of $210 \mathrm{ppm}$ (see text), which is the basis for the solid red line. All other calculations are scaled to this line assuming that the photon count rate scales linearly with transmission. Note that the optimum performance for the current set of mirrors would occur for slightly more transmissive (less reflective) optics, with a minimum at approximately twice $(400 \mathrm{ppm})$ the measured transmission of $200 \mathrm{ppm}$.

tially free from the potential interferences or artifacts of those methods.

Ultraviolet BBCEAS measurements would be appropriate for more rapid sampling of ambient, background $\mathrm{CH}_{2} \mathrm{O}$ concentrations if its $2 \sigma$ detection limit could be improved by approximately a factor of 3 to achieve $100 \mathrm{pptv}$ in $1 \mathrm{~min}$. This limit would require an increase of the effective path length or an increase of the optical power at the detector. The first possibility would require a factor of 9 decrease in absorption and scattering losses in the mirror coating, with unchanged transmission and reflectivity. Figure 9 demonstrates the relationship between $\alpha_{\min }$, mirror transmission, and the sum of mirror absorption and scattering, calculated from Eq. (3). The second possibility would require a factor of 9 increase in optical power at the detector, for a system following the shot noise limit. This would need to be achieved through improvements in the light source power, geometric light collection, and optical filtering. More powerful laser-driven light sources or ultraviolet LEDs may be available in the future to partially satisfy this requirement. Super-continuum laser light sources are available in the visible spectral region and 
offer much higher optical power output and spatial coherence, allowing them to be more efficiently coupled into an optical cavity. Such sources are not available in the ultraviolet spectral region but may be in the future.

The ultraviolet light source and measurements presented here have strong potential for ambient, high time resolution measurements of aerosol optical extinction in the ultraviolet spectral region, where brown carbon absorption is important. Previous measurements have reported aerosol extinction and retrievals of complex refractive indices from 360 to $420 \mathrm{~nm}$ (Washenfelder et al., 2013; Flores et al., 2014a, b). The ultraviolet BBCEAS instrument will allow those measurements to be extended to $315 \mathrm{~nm}$. The $1 \sigma$ precision of $1.8 \times 10^{-8}$ and $6 \times 10^{-9} \mathrm{~cm}^{-1}\left(1.8\right.$ and $\left.0.6 \mathrm{Mm}^{-1}\right)$ per min for single pixels $(0.05 \mathrm{~nm})$ at 315 and $330 \mathrm{~nm}$ determined from the Allan deviation is appropriate for aerosol extinction measurements even in clean environments. These values would be further improved by averaging multiple pixels. Field measurements of dry aerosol extinction and angstrom exponent at $360-420 \mathrm{~nm}$ measured in the rural southeastern USA (Washenfelder et al., 2015) indicate that the extinction at $315 \mathrm{~nm}$ would be $1 \times 10^{-7}-2 \times 10^{-6} \mathrm{~cm}^{-1}(10$ $200 \mathrm{Mm}^{-1}$ ). These values are easily measurable with the current detection limit, with signal-to-noise ratio of 6-110 (17$300)$ at $315 \mathrm{~nm}(330 \mathrm{~nm})$ for 1 min ground measurements and 6-110 (12-250) for 1s aircraft measurements.

Acknowledgements. We thank Max McGillen for preparation of formaldehyde samples. We thank Andrew Langford for technical discussions. We thank Ryan Thalman and three anonymous reviewers for their discussion comments. R. A. Washenfelder, A. R. Attwood, and S. S. Brown acknowledge financial support from the NOAA Atmospheric Chemistry and Climate Program. This research was supported by research grants from the USAIsrael Binational Science Foundation (BSF) grant no. 2012013. Y. Rudich acknowledges support from the Grand Center at the Weizmann Institute and the Dollond Charitable Trust.

Edited by: D. Heard

\section{References}

Allan, D. W.: Statistics of atomic frequency standards, Pr. Inst. Electr. Elect., 54, 221-230, 1966.

Axson, J. L., Washenfelder, R. A., Kahan, T. F., Young, C. J., Vaida, V., and Brown, S. S.: Absolute ozone absorption cross section in the Huggins Chappuis minimum (350-470 nm) at 296 K, Atmos. Chem. Phys., 11, 11581-11590, doi:10.5194/acp11-11581-2011, 2011.

Ball, S. M., Langridge, J. M., and Jones, R. L.: Broadband cavity enhanced absorption spectroscopy using light emitting diodes, Chem. Phys. Lett., 398, 68-74, 2004.

Bovensmann, H., Burrows, J. P., Buchwitz, M., Frerick, J., Noel, S., Rozanov, V. V., Chance, K. V., and Goede, A. P. H.: SCIA-
MACHY: Mission objectives and measurement modes, J. Atmos. Sci., 56, 127-150, 1999.

Burrows, J. P., Weber, M., Buchwitz, M., Rozanov, V., LadstatterWeissenmayer, A., Richter, A., DeBeek, R., Hoogen, R., Bramstedt, K., Eichmann, K. U., and Eisinger, M.: The global ozone monitoring experiment (GOME): Mission concept and first scientific results, J. Atmos. Sci., 56, 151-175, 1999.

Chance, K., Palmer, P. I., Spurr, R. J. D., Martin, R. V., Kurosu, T. P., and Jacob, D. J.: Satellite observations of formaldehyde over North America from GOME, Geophys. Res. Lett., 27, 34613464, 2000.

Chen, J. and Venables, D. S.: A broadband optical cavity spectrometer for measuring weak near-ultraviolet absorption spectra of gases, Atmos. Meas. Tech., 4, 425-436, doi:10.5194/amt-4-4252011, 2011.

Chen, J., Wenger, J. C., and Venables, D. S.: Near-ultraviolet absorption cross sections of nitrophenols and their potential influence on tropospheric oxidation capacity, J. Phys. Chem. A, 115, 12235-12242, 2011.

Fan, Q. and Dasgupta, P. K.: Continuous automated-determination of atmospheric formaldehyde at the parts per trillion level, Anal. Chem., 66, 551-556, doi:10.1021/ac00076a021, 1994.

Fiedler, S. E., Hese, A., and Ruth, A. A.: Incoherent broad-band cavity-enhanced absorption spectroscopy, Chem. Phys. Lett., 371, 284-294, doi:10.1016/S0009-2614(03)00263-X, 2003.

Flores, J. M., Washenfelder, R. A., Adler, G., Lee, H. J., Segev, L., Laskin, J., Laskin, A., Nizkorodov, S. A., Brown, S. S., and Rudich, Y.: Complex refractive indices in the near-ultraviolet spectral region of biogenic secondary organic aerosol aged with ammonia, Phys. Chem. Chem. Phys., 16, 10629-10642, doi:10.1039/C4cp01009d, 2014a.

Flores, J. M., Zhao, D. F., Segev, L., Schlag, P., Kiendler-Scharr, A., Fuchs, H., Watne, ̊. K., Bluvshtein, N., Mentel, Th. F., Hallquist, M., and Rudich, Y.: Evolution of the complex refractive index in the UV spectral region in ageing secondary organic aerosol, Atmos. Chem. Phys., 14, 5793-5806, doi:10.5194/acp14-5793-2014, 2014b.

Fried, A., Sewell, S., Henry, B., Wert, B. P., Gilpin, T., and Drummond, J. R.: Tunable diode laser absorption spectrometer for ground-based measurements of formaldehyde, J. Geophys. Res., 102, 6253-6266, doi:10.1029/96jd01580, 1997.

Fried, A., Wert, B., Walega, J., Richter, D., and Potter, B.: Airborne measurements of formaldehyde employing a high performance tunable diode laser absorption system, P. Soc. Photo-Opt. Ins., 4817, 177-183, doi:10.1117/12.452084, 2002.

Fuchs, H., Dube, W. P., Lerner, B. M., Wagner, N. L., Williams, E. J., and Brown, S. S.: A sensitive and versatile detector for atmospheric $\mathrm{NO}_{2}$ and $\mathrm{NO}_{x}$ based on blue diode laser cavity ring-down spectroscopy, Environ. Sci. Technol., 43, 7831-7836, doi:10.1021/Es902067h, 2009.

Fung, K. and Grosjean, D.: Determination of nanogram amounts of carbonyls as 2,4-dinitrophenylhydrazones by high-performance liquid-chromatography, Anal. Chem., 53, 168-171, 1981.

Gherman, T., Venables, D. S., Vaughan, S., Orphal, J., and Ruth, A. A.: Incoherent broadband cavity-enhanced absorption spectroscopy in the near-ultraviolet: Application to $\mathrm{HONO}$ and $\mathrm{NO}_{2}$, Environ. Sci. Technol., 42, 890-895, 2008. 
Grosjean, E., Grosjean, D., Fraser, M. P., and Cass, G. R.: Air quality model evaluation data for organics: $2 . \mathrm{C}_{1}-\mathrm{C}_{14}$ carbonyls in Los Angeles air, Environ. Sci. Technol., 30, 2687-2703, 1996.

Hak, C., Pundt, I., Trick, S., Kern, C., Platt, U., Dommen, J., Ordóñez, C., Prévôt, A. S. H., Junkermann, W., Astorga-Lloréns, C., Larsen, B. R., Mellqvist, J., Strandberg, A., Yu, Y., Galle, B., Kleffmann, J., Lörzer, J. C., Braathen, G. O., and Volkamer, R.: Intercomparison of four different in-situ techniques for ambient formaldehyde measurements in urban air, Atmos. Chem. Phys., 5, 2881-2900, doi:10.5194/acp-5-2881-2005, 2005.

Heckel, A., Richter, A., Tarsu, T., Wittrock, F., Hak, C., Pundt, I., Junkermann, W., and Burrows, J. P.: MAX-DOAS measurements of formaldehyde in the Po-Valley, Atmos. Chem. Phys., 5, 909 918, doi:10.5194/acp-5-909-2005, 2005.

Herndon, S. C., Zahniser, M. S., Nelson, D. D., Shorter, J., McManus, J. B., Jimenez, R., Warneke, C., and de Gouw, J. A.: Airborne measurements of $\mathrm{HCHO}$ and $\mathrm{HCOOH}$ during the New England Air Quality Study 2004 using a pulsed quantum cascade laser spectrometer, J. Geophys. Res., 112, D10S03, doi:10.1029/2006JD007600, 2007.

Hottle, J. R., Huisman, A. J., Digangi, J. P., Kammrath, A., Galloway, M. M., Coens, K. L., and Keutsch, F. N.: A laser induced fluorescence-based instrument for in-situ measurements of atmospheric formaldehyde, Environ. Sci. Technol., 43, 790-795, 2009.

Islam, M., Ciaffoni, L., Hancock, G., and Ritchie, G. A. D.: Demonstration of a novel laser-driven light source for broadband spectroscopy between $170 \mathrm{~nm}$ and $2.1 \mu \mathrm{m}$, Analyst, 138, 4741-4745, 2013.

Junkermann, W. and Burger, J. M.: A new portable instrument for continuous measurement of formaldehyde in ambient air, J. Atmos. Ocean Tech., 23, 38-45, doi:10.1175/Jtech1831.1, 2006.

Kahan, T. F., Washenfelder, R. A., Vaida, V., and Brown, S. S.: Cavity-enhanced measurements of hydrogen peroxide absorption cross sections from 353 to $410 \mathrm{~nm}$, J. Phys. Chem. A, 116, 59415947, doi:10.1021/Jp2104616, 2012.

Karl, T., Jobson, T., Kuster, W. C., Williams, E., Stutz, J., Shetter, R., Hall, S. R., Goldan, P., Fehsenfeld, F., and Lindinger, W.: Use of proton-transfer-reaction mass spectrometry to characterize volatile organic compound sources at the La Porte super site during the Texas Air Quality Study 2000, J. Geophys. Res., 108, 4508, doi:10.1029/2002jd003333, 2003.

Kelly, T. J. and Fortune, C. R.: Continuous monitoring of gaseous formaldehyde using an improved fluorescence approach, Int. J. Environ. An. Ch., 54, 249-263, doi:10.1080/03067319408034093, 1994.

Kok, G. L., Walega, J. G., Heikes, B. G., Lind, J. A., and Lazrus, A. L.: Measurements of hydrogen peroxide and formaldehyde in Glendora, California, Aerosol Sci. Tech., 12, 49-55, 1990.

Kraus, S. G.: DOASIS: A Framework Design for DOAS, Dissertation, University of Mannheim, Mannheim, Germany, 2006.

Langridge, J. M., Ball, S. M., and Jones, R. L.: A compact broadband cavity enhanced absorption spectrometer for detection of atmospheric $\mathrm{NO}_{2}$ using light emitting diodes, Analyst, 131, 916922, 2006

Langridge, J. M., Gustafsson, R. J., Griffiths, P. T., Cox, R. A., Lambert, R. M., and Jones, R. L.: Solar driven nitrous acid formation on building material surfaces containing titanium dioxide: A con- cern for air quality in urban areas?, Atmos. Environ., 43, 51285131, 2009.

Lee, Y. N., Zhou, X., Kleinman, L. I., Nunnermacker, L. J., Springston, S. R., Daum, P. H., Newman, L., Keigley, W. G., Holdren, M. W., Spicer, C. W., Young, V., Fu, B., Parrish, D. D., Holloway, J., Williams, J., Roberts, J. M., Ryerson, T. B., and Fehsenfeld, F. C.: Atmospheric chemistry and distribution of formaldehyde and several multioxygenated carbonyl compounds during the 1995 Nashville Middle Tennessee Ozone Study, J. Geophys. Res., 103, 22449-22462, 1998.

Meller, R. and Moortgat, G. K.: Temperature dependence of the absorption cross sections of formaldehyde between 223 and $323 \mathrm{~K}$ in the wavelength range $225-375 \mathrm{~nm}$, J. Geophys. Res., 105, 7089-7101, 2000.

Min, K.-E., Washenfelder, R. A., Dubé, W. P., Langford, A. O., Edwards, P. M., Zarzana, K. J., Stutz, J., Lu, K., Rohrer, F., Zhang, Y., and Brown, S. S.: A broadband cavity enhanced absorption spectrometer for aircraft measurements of glyoxal, methylglyoxal, nitrous acid, nitrogen dioxide, and water vapor, Atmos. Meas. Tech. Discuss., 8, 11209-11254, doi:10.5194/amtd8-11209-2015, 2015.

Mohlmann, G. R.: Formaldehyde detection in air by laser-induced fluorescence, Appl. Spectrosc., 39, 98-101, 1985.

Platt, U., Perner, D., and Patz, H. W.: Simultaneous measurement of atmospheric $\mathrm{CH}_{2} \mathrm{O}, \mathrm{O}_{3}$, and $\mathrm{NO}_{2}$ by differential optical absorption, J. Geophys. Res., 84, 6329-6335, 1979.

Shardanand, S. and Rao, A. D. P.: Absolute Rayleigh scattering cross sections of gases and freons of stratospheric interest in the visible and ultraviolet regions, NASA Technical Note, 1977.

Shim, C., Wang, Y. H., Choi, Y., Palmer, P. I., Abbot, D. S., and Chance, K.: Constraining global isoprene emissions with Global Ozone Monitoring Experiment (GOME) formaldehyde column measurements, J. Geophys. Res., 110, D24301, doi:10.1029/2004JD005629, 2005.

Sneep, M. and Ubachs, W.: Direct measurement of the Rayleigh scattering cross section in various gases, J. Quant. Spectrosc. Ra., 92, 293-310, 2005.

Spaulding, R. S., Talbot, R. W., and Charles, M. J.: Optimization of a mist chamber (cofer scrubber) for sampling water-soluble organics in air, Environ. Sci. Technol., 36, 1798-1808, 2002.

Steinbacher, M., Dommen, J., Ammann, C., Spirig, C., Neftel, A., and Prevot, A. S. H.: Performance characteristics of a protontransfer-reaction mass spectrometer (PTR-MS) derived from laboratory and field measurements, Int. J. Mass Spectrom., 239, 117-128, doi:10.1016/j.ijms.2004.07.015, 2004.

Thalman, R. and Volkamer, R.: Inherent calibration of a blue LED-CE-DOAS instrument to measure iodine oxide, glyoxal, methyl glyoxal, nitrogen dioxide, water vapour and aerosol extinction in open cavity mode, Atmos. Meas. Tech., 3, 1797-1814, doi:10.5194/amt-3-1797-2010, 2010.

Thalman, R., Zarzana, K. J., Tolbert, M. A., and Volkamer, R.: Rayleigh scattering cross-section measurements of nitrogen, argon, oxygen and air, J. Quant. Spectrosc. Ra., 147, 171-177, doi:10.1016/j.jqsrt.2014.05.030, 2014.

Vandaele, A. C., Hermans, C., Simon, P. C., Carleer, M., Colin, R., Fally, S., Merienne, M. F., Jenouvrier, A., and Coquart, B.: Measurements of the $\mathrm{NO}_{2}$ absorption cross-section from $42000 \mathrm{~cm}^{-1}$ to $10000 \mathrm{~cm}^{-1}(238-1000 \mathrm{~nm})$ at $220 \mathrm{~K}$ and 294 K, J. Quant. Spectrosc. Ra., 59, 171-184, 1998. 
Varma, R. M., Venables, D. S., Ruth, A. A., Heitmann, U., Schlosser, E., and Dixneuf, S.: Long optical cavities for openpath monitoring of atmospheric trace gases and aerosol extinction, Appl. Optics, 48, 159-171, 2009.

Venables, D. S., Gherman, T., Orphal, J., Wenger, J. C., and Ruth, A. A.: High sensitivity in situ monitoring of $\mathrm{NO}_{3}$ in an atmospheric simulation chamber using incoherent broadband cavity-enhanced absorption spectroscopy, Environ. Sci. Technol., 40, 6758-6763, 2006.

Warneke, C., Veres, P., Holloway, J. S., Stutz, J., Tsai, C., Alvarez, S., Rappenglueck, B., Fehsenfeld, F. C., Graus, M., Gilman, J. B., and de Gouw, J. A.: Airborne formaldehyde measurements using PTR-MS: calibration, humidity dependence, intercomparison and initial results, Atmos. Meas. Tech., 4, 23452358, doi:10.5194/amt-4-2345-2011, 2011.

Washenfelder, R. A., Langford, A. O., Fuchs, H., and Brown, S. S.: Measurement of glyoxal using an incoherent broadband cavity enhanced absorption spectrometer, Atmos. Chem. Phys., 8, 7779-7793, doi:10.5194/acp-8-7779-2008, 2008.

Washenfelder, R. A., Young, C. J., Brown, S. S., Angevine, W. M., Atlas, E. L., Blake, D. R., Bon, D. M., Cubison, M. J., de Gouw, J. A., Dusanter, S., Flynn, J., Gilman, J. B., Graus, M., Griffith, S., Grossberg, N., Hayes, P. L., Jimenez, J. L., Kuster, W. C., Lefer, B. L., Pollack, I. B., Ryerson, T. B., Stark, H., Stevens, P. S., and Trainer, M. K.: The glyoxal budget and its contribution to organic aerosol for Los Angeles, California, during CalNex 2010, J. Geophys. Res., 116, D00V02, doi:10.1029/2011JD016314, 2011.

Washenfelder, R. A., Flores, J. M., Brock, C. A., Brown, S. S., and Rudich, Y.: Broadband measurements of aerosol extinction in the ultraviolet spectral region, Atmos. Meas. Tech., 6, 861-877, doi:10.5194/amt-6-861-2013, 2013.

Washenfelder, R. A., Attwood, A. R., Brock, C. A., Guo, H., Xu, L., Weber, R. J., Ng, N. L., Allen, H. M., Ayres, B. R., Baumann, K., Cohen, R. C., Draper, D. C., Duffey, K. C., Edgerton, E., Fry, J. L., Hu, W. W., Jimenez, J. L., Palm, B. B., Romer, P., Stone, E. A., Wooldridge, P. J., and Brown, S. S.: Biomass burning dominates brown carbon absorption in the rural southeastern United States, Geophys. Res. Lett., 42, 653-664, 2015.
Weibring, P., Richter, D., Walega, J. G., and Fried, A.: Airborne Difference Frequency Spectrometer for Ultra Sensitive Formaldehyde Measurements, 2007 Conference on Lasers \& Electro-Optics/Quantum Electronics and Laser Science Conference (Cleo/Qels 2007), Vol. 1-5, 1607-1608, 2007.

Wert, B. P., Fried, A., Henry, B., and Cartier, S.: Evaluation of inlets used for the airborne measurement of formaldehyde, J. Geophys. Res., 107, 4163, doi:10.1029/2001jd001072, 2002.

Wisthaler, A., Apel, E. C., Bossmeyer, J., Hansel, A., Junkermann, W., Koppmann, R., Meier, R., Müller, K., Solomon, S. J., Steinbrecher, R., Tillmann, R., and Brauers, T.: Technical Note: Intercomparison of formaldehyde measurements at the atmosphere simulation chamber SAPHIR, Atmos. Chem. Phys., 8, 21892200, doi:10.5194/acp-8-2189-2008, 2008.

Wittrock, F., Richter, A., Oetjen, H., Burrows, J. P., Kanakidou, M., Myriokefalitakis, S., Volkamer, R., Beirle, S., Platt, U., and Wagner, T.: Simultaneous global observations of glyoxal and formaldehyde from space, Geophys. Res. Lett., 33, L16804, doi:10.1029/2006GL026310, 2006.

Yokelson, R. J., Griffith, D. W. T., and Ward, D. E.: Openpath Fourier transform infrared studies of large-scale laboratory biomass fires, J. Geophys. Res., 101, 21067-21080, doi:10.1029/96jd01800, 1996.

Young, C. J., Washenfelder, R. A., Roberts, J. M., Mielke, L. H., Osthoff, H. D., Tsai, C., Pikelnaya, O., Stutz, J., Veres, P. R., Cochran, A. K., VandenBoer, T. C., Flynn, J., Grossberg, N., Haman, C. L., Lefer, B., Stark, H., Graus, M., de Gouw, J., Gilman, J. B., Kuster, W. C., and Brown, S. S.: Vertically resolved measurements of nighttime radical reservoirs in Los Angeles and their contribution to the urban radical budget, Environ. Sci. Technol., 46, 10965-10973, 2012.

Zhu, H. L. and Blackborow, P.: LDLS sheds light on analyticalsciences applications, Laser Focus World, 47, 53-55, 2011. 